\title{
Cardiac Computerized Tomographic Angiography
}

National Cancer Institute

\section{Source}

National Cancer Institute. Cardiac Computerized Tomographic Angiography. NCI

Thesaurus. Code C100071.

An imaging technique of the heart and neighboring structures involving helical computed tomography and computer software to generate high-resolution 2-dimensional and 3dimensional images. (ACC) 